\title{
Amino acid utilisation and deamination of glutamine and asparagine by Helicobacter pylori
}

\author{
R. M. STARK, M.-S. SULEIMAN*, I. J. HASSAN†, J. GREENMAN and M. R. MILLAR ${ }^{\dagger}$ \\ Faculty of Science, Department of Biological Sciences, University of the West of England, Coldharbour Lane, \\ Frenchay, Bristol BS16 10Y, *Department of Cardiac Surgery and ${ }^{\dagger}$ Department of Pathology and Microbiology, \\ University of Bristol, Bristol Royal Infirmary, Marlborough Street, Bristol BS2 8HW
}

\begin{abstract}
Helicobacter pylori can utilise amino acids as the sole carbon energy source. The present study demonstrated that $H$. pylori grown in continuous culture in a defined medium containing glucose and amino acids utilised alanine, arginine, asparagine, aspartate, glutamine, glutamate, proline and serine. Specific asparaginase and glutaminase enzymes deaminated asparagine and glutamine respectively to aspartate and glutamate, with the production of ammonia. The glutaminase activity was inhibited by 6-diazo-5-oxo-Lnorleucine. All the 13 strains of $H$. pylori tested produced both glutaminase and asparaginase activities. Glutamine is important in the health of the gastric and intestinal mucosa and is a primary energy source for lymphocytes. Depletion of glutamine at the site of $H$. pylori infection may be of significance in the pathogenesis of $H$. pyloriassociated diseases such as peptic ulcer and gastric cancer.
\end{abstract}

\section{Introduction}

Helicobacter pylori is a gram-negative, curved, microaerophilic eubacterium. It was first isolated in 1982 from peptic ulcer patients [1]. The organism colonises the mucosal layer of the gastric antrum and has been implicated in the pathogenesis of type B (non-autoimmune) gastritis, gastric and duodenal ulcers $[1,2]$ and stomach cancer $[3,4]$.

Several potential virulence factors have been identified, including a vacuolating cytotoxin (VacA) [5], a cytotoxin-associated gene product (CagA) [6], acid and alkaline phosphatases and urease [7]. The urease enzyme of $H$. pylori is constitutively produced at high levels accounting for up to $6 \%$ of the total cell protein [8]. The hydrolysis of urea may produce a 'cloud of ammonia' [9] that protects the organism from the highly acidic environment of the stomach during the initial stages of colonisation. Raised concentrations of ammonia increase the adherence of $H$. pylori to epithelial cells, are toxic to mammalian cells [10] and cause weakening of the tight junctions between cells [8]. Therefore, ammonia production has been implicated in the pathogenesis of $H$. pylori-associated diseases.

Received 1 Nov. 1996; revised version accepted 17 Feb. 1997.

Corresponding author: Dr M. R. Millar.
$H$. pylori was initially thought to lack fermentative pathways for saccharides $[11,2]$, but has been shown to utilise glucose $[12,13]$. Investigations into the nutritional requirements of $H$. pylori have revealed that it is able to grow on defined glucose-free medium [14]; therefore it is able to utilise amino acids as the sole carbon energy source. The amino acids that $H$. pylori uses as carbon energy sources have recently been described. Arginine, aspartate, glutamate and serine are utilised with asparaginase and glutaminase enzyme production yielding aspartate from asparagine and glutamate from glutamine respectively [15]. This study reports (i) the continuous culture of $H$. pylori in a defined medium; (ii) confirmation of the utilisation of arginine, aspartate, glutamate and serine; (iii) confirmation of the production of glutaminase and asparaginase by measuring glutamate, aspartate and ammonia production and glutamine and asparagine consumption; (iv) the utilisation of alanine and proline as carbon/nitrogen sources; and (v) the inhibition of glutaminase activity by 6-diazo-5-oxo-L-norleucine.

\section{Materials and methods}

\section{Bacterial strains}

Type strains of $H$. pylori (NCTC 11637, 11638 and 11916) and clinical isolates (N118, G2245, G2778, G2580, G2985, G3266 and G3571) were subcultured every 3-5 days on to Columbia Agar Base (CM 331, Unipath) supplemented with horse blood 5\%. Plates 
were incubated in a micro-aerophilic environment at $37^{\circ} \mathrm{C}$. $H$. pylori NCTC 11637 was used for all experiments unless otherwise stated.

\section{Batch culture}

H. pylori harvested from plate cultures was used to inoculate $250 \mathrm{ml}$ of Brucella Broth (0495-17-3, Difco) containing $\beta$-cyclodextrin (C-4767, Sigma) $0.2 \%$ and $H$. pylori-selective supplement (SR147E, Unipath) to give just visible turbidity $\left(c .10^{7} \mathrm{cfu} / \mathrm{ml}\right)$. Cultures were sparged with a mixture of $\mathrm{O}_{2} \quad 5 \%, \mathrm{CO}_{2} \quad 10 \%, \mathrm{~N}_{2} 85 \%$ at a rate of $75 \mathrm{ml} / \mathrm{min}$ and agitated in an orbital shaker at $100 \mathrm{rpm}$. Broth cultures were harvested at $72-96 \mathrm{~h}$ and the bacterial cells were concentrated by centrifugation.

\section{Growth in continuous culture}

H. pylori was established in continuous culture as previously described, with filter-sterilised Brucella broth supplemented with fetal calf serum $1 \%$ [16]. After 6 days the undefined Brucella broth was replaced with a defined medium (Table 1) with constituents based on the published reports of the nutritional and growth supplement requirements of $H$. pylori $[14,17,18]$. This medium was filter sterilised. The defined medium was added at a continuous flow rate to give a net dilution rate (D) of $0.03 \mathrm{~h}$.

\section{Estimation of culture biomass and ammonia}

At intervals, samples of the chemostat culture were removed. The biomass was estimated by measuring the $\mathrm{OD}_{540}$. Ammonia concentrations in samples was determined by the Berthelot (phenol-hypochlorite) method [19].

\section{HPLC analysis}

Amino acids were determined by methods reported previously [20]. Essentially, for analysis of deamination of glutamine and asparagine, samples were deproteinised by ultrafiltration (Millipore $10 \mathrm{~K}$ mol. wt cut-off ultrafiltration unit, $8500 \mathrm{~g}, 15 \mathrm{~min}$ ). Samples of $25 \mu \mathrm{l}$ of ultrafiltrate were freeze-dried. The free amino acids were derivatised with $100 \mu \mathrm{l}$ of phenylisothiocyanate solution. Samples $(10 \mu \mathrm{l})$ of the derivatised amino acids were injected on to and separated by HPLC. Quantitative analysis was carried out by comparing samples to amino acid standards ' $\mathrm{H}$ ' (No. NCI 0180, Pierce, Rockford, IL, USA). Analysis of continuous culture supernates was done similarly.

\section{Determination of protein concentration}

The protein concentration of cell suspensions for the determination of specific activities of $H$. pylori strains was estimated by a modified Lowry method (Sigma P5656).

\section{Determination of specificities of deaminase}

Each of 20 amino acids was tested individually as substrate in an assay consisting of: amino acid substrate $(0.01 \mathrm{M})$, sodium phosphate buffer $(\mathrm{pH} 7.0,0.1 \mathrm{M})$ and bacterial cells (broth culture) at a concentration giving a final $\mathrm{OD}_{540}$ of 0.5 in the reaction mixture. Incubation was at $37^{\circ} \mathrm{C}$. At time 0 (blank) and after $1 \mathrm{~h}$ the ammonia concentration was determined in duplicate 100- $\mu$ l samples.

The asparaginase and glutaminase enzyme activities of $H$. pylori strains were determined. $H$. pylori was grown on Columbia blood agar plates for $76 \mathrm{~h}$ and harvested into sterile phosphate-buffered saline to give a final $\mathrm{OD}_{540}$ of 1.0 . The protein concentration of

Table 1. Constituents of defined medium for growth of $H$. pylori in continuous culture

\begin{tabular}{|c|c|c|c|c|}
\hline Constituent & Concentration $(\mathrm{mg} / \mathrm{L})$ & Molarity (mM) & Constituent & Concentration $(\mathrm{mg} / \mathrm{L})$ \\
\hline L-Alanine & 150 & $(1.68)$ & Thiamine & 0.03 \\
\hline L-Arginine & 150 & $(0.71)$ & Hypoxanthine & 10 \\
\hline L-Asparagine & 70 & $(0.52)$ & Nytropyrin & 0.5 \\
\hline L-Aspartic acid & 150 & (1.11) & Adenine & 10 \\
\hline L-Cysteine & 70 & $(0.45)$ & Uracil & 10 \\
\hline L-Cystine & 70 & $(0.29)$ & Guanine & 10 \\
\hline L-Glutamic acid & 150 & (1.02) & Xanthine & 10 \\
\hline L-Glutamine & 150 & $(1.02)$ & & \\
\hline Glycine & 70 & $(0.93)$ & $\mathrm{NaCl}$ & 4500 \\
\hline L-Histidine. $\mathrm{HCl}$ & 70 & $(0.45)$ & $\mathrm{KCl}$ & 4000 \\
\hline L-Isoleucine & 150 & (1.14) & $\mathrm{K}_{2} \mathrm{HPO}_{4}$ & 500 \\
\hline L-Leucine & 150 & (1.14) & $\mathrm{MgSO}_{4} \cdot 7 \mathrm{H}_{2} \mathrm{O}$ & 100 \\
\hline L-Lysine & 150 & $(1.02)$ & $\mathrm{CaCl}_{2}$ & 20 \\
\hline L-Methionine & 70 & $(0.47)$ & $\mathrm{MnCl}_{2}$ & 10 \\
\hline L-Phenylalanine & 150 & $(0.91)$ & $\mathrm{CoCl}_{2}$ & 0.2 \\
\hline L-Proline & 150 & $(1.30)$ & $\mathrm{CuCl}_{2}$ & 0.01 \\
\hline L-Serine & 150 & $(1.42)$ & $\mathrm{ZnSO}_{4}$ & 0.1 \\
\hline L-Threonine & 150 & $(1.26)$ & $\mathrm{NiCl}_{2}$ & 0.02 \\
\hline L-Tryptophan & 70 & $(0.34)$ & $\mathrm{Na}_{2} \mathrm{MoO}_{4}$ & 0.03 \\
\hline L-Tyrosine & 150 & $(0.82)$ & $\mathrm{FeSO}_{4}$ & 2.0 \\
\hline L-Valine & 150 & $(1.28)$ & $\mathrm{H}_{3} \mathrm{BO}_{4}$ & 0.3 \\
\hline$\beta$-Cyclodextrin & 1000 & & Glucose & 2000 \\
\hline
\end{tabular}


each suspension was estimated by the Lowry method. Each strain was tested individually in an assay consisting of: amino acid (asparagine or glutamine) substrate $(0.01 \mathrm{M})$, sodium phosphate buffer $(\mathrm{pH} 7.0$, $0.1 \mathrm{M})$ and a bacterial concentration giving an $\mathrm{OD}_{540}$ of 0.5 in the reaction mixture. Incubation was at $37^{\circ} \mathrm{C}$. At time 0 (blank) and after $1 \mathrm{~h}$ the ammonia concentration was determined in duplicate $100-\mu 1$ samples.

\section{Glutaminase and asparaginase assay}

Deaminase activity was estimated in $0.1 \mathrm{M}$ sodium phosphate buffer, $\mathrm{pH} 7.0$, containing $0.01 \mathrm{M}$ glutamine or asparagine substrate and a bacterial concentration giving an $\mathrm{OD}_{540}$ of 0.5 in the reaction mixture. The rates of change of amino acid concentration in the absence of bacterial cells or bacterial cells without the addition of amino acid substrate were also determined. Samples were removed at intervals from 0 to $7 \mathrm{~h}$ centrifuged (15000 $\mathrm{g}$ for $2 \mathrm{~min}$ ), and the supernates were removed and stored at $-70^{\circ} \mathrm{C}$ before analysis. Samples were later thawed and analysed for ammonia and analysed by HPLC for glutamine and glutamate or asparagine and aspartate. Experiments were carried out in duplicate.

\section{Inhibition of glutaminase activity by 6-diazo-5- oxo-L-norleucine}

The effect of the glutaminase specific inhibitor, 6diazo-5-oxo-L-norleucine (DON) on enzyme activity was investigated. Glutamine and asparagine were assayed as for glutaminase and asparaginase assay with the following modifications. The cell suspension was pre-incubated in the presence and absence of $0.06 \mathrm{mM}$ DON for $15 \mathrm{~min}$. This concentration of DON had been reported previously to inhibit the activity of glutaminases [21]; the reaction was started with the addition of the substrate (time 0 ) and the ammonia concentrations were determined in duplicate $50-\mu 1$ samples at intervals from 0 (blank) to $145 \mathrm{~min}$ after the addition of glutamine or asparagine.

\section{Chemostat purity}

The purity of the chemostat broth culture was checked each day by inoculation of Columbia blood agar which was then incubated aerobically and micro-aerophilically for up to 5 days. Chemostat broth culture samples and micro-aerophilically incubated agar plate cultures were tested for urease, catalase and oxidase activities and gram-stain morphology.

\section{Results}

\section{Continuous culture}

In the continuous culture experiments, growth in undefined brucella broth with fetal calf serum $1 \%$ was followed by the transition to a fully defined medium. Throughout the experiment, the biomass, ammonia concentration and $\mathrm{pH}$ of the culture were measured at intervals. Growth in the undefined medium did not require the addition of acid or base, as the $\mathrm{pH}$ remained approximately constant within the set limits (6.5-7.2). Growth in the defined medium (started at day 6) did require the addition of acid and base to maintain the $\mathrm{pH}$. The transition from undefined to defined media was made at a dilution rate of $0.03 \mathrm{~h}$ $(21 \mathrm{ml} / \mathrm{h}$ with $700 \mathrm{ml}$ culture volume). After 18 days of defined medium addition, the residual concentration of brucella broth was therefore $<0.1 \%$.

The concentration of ammonia in the brucella brothfetal calf serum prior to inoculation with $H$. pylori was $c .4 \mathrm{mM}$, and this increased to $18 \mathrm{mM} 7$ days after inoculation. The concentration of ammonia detected in the urea-free defined medium before addition to the chemostat culture vessel was $<1 \mathrm{mM}$. The low level of ammonia detected was probably due to hydrolysis of glutamine that occurs naturally in solution. The concentration of ammonia gradually decreased during the transition to defined medium, declining to $5.9 \mathrm{mM}$.

Twelve days after inoculation of the chemostat a biofilm was observed to have formed on the vessel wall. This was most marked at the gas/liquid interface where foaming occurred. Build-up of the biofilm led to inconsistent biomass determinations by optical density, as occasionally sections of biofilm became dislodged. Eventually the overflow (waste) line of the chemostat became blocked with build up of biofilm 24 days after inoculation, and the experiment was terminated. Regular checks of purity confirmed the culture to be $H$. pylori.

Amino acid analysis of the continuous culture supernate (Fig. 1) revealed that it had been almost totally depleted of alanine, arginine, asparagine, aspartate, glutamate, glutamine, proline and serine. On the other

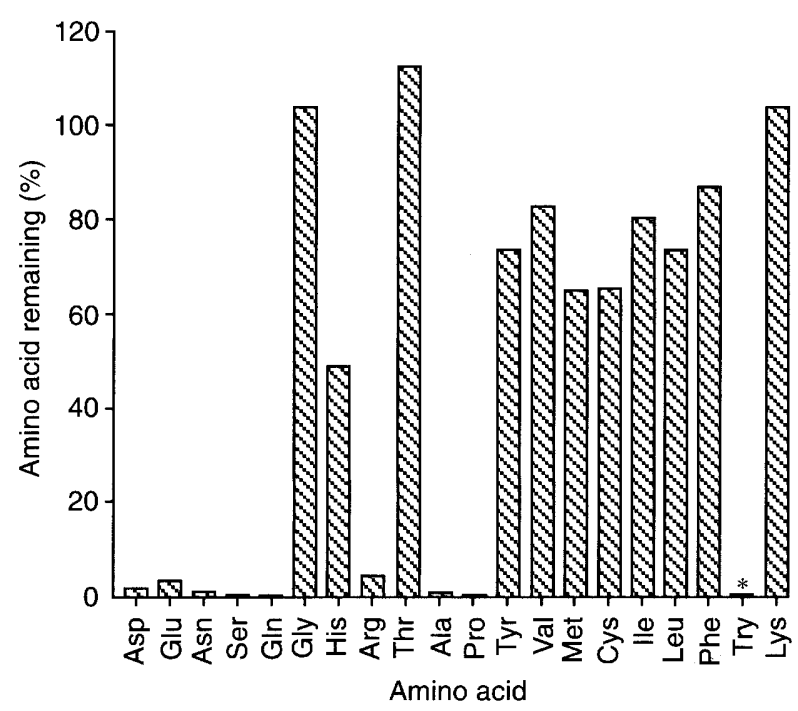

Fig. 1. Percentage of amino acids remaining in culture supernate of $H$. pylori NCTC 11637 grown in defined medium in continuous culture. ${ }^{*}$, not determined. 
hand, there were no significant changes in the concentrations of glycine, lysine and threonine.

\section{Deamination of amino acids}

Of all the amino acids tested for deamination by ammonia production only glutamine (relative rate 1) and asparagine (relative rate $c .0 .75$ ) were shown to be deaminated by $H$. pylori. The relative rate of ammonia production from all other amino acids was $<10 \%$ of that of glutamine (Fig. 2). All the 13 strains that were tested for the production of glutaminase and asparaginase activities produced detectable levels of activity, albeit with differing ratios and specific activities (Table 2).

\section{Glutaminase and asparaginase activity}

The rate of ammonia production from glutamine or asparagine incubated with bacterial cell suspension was

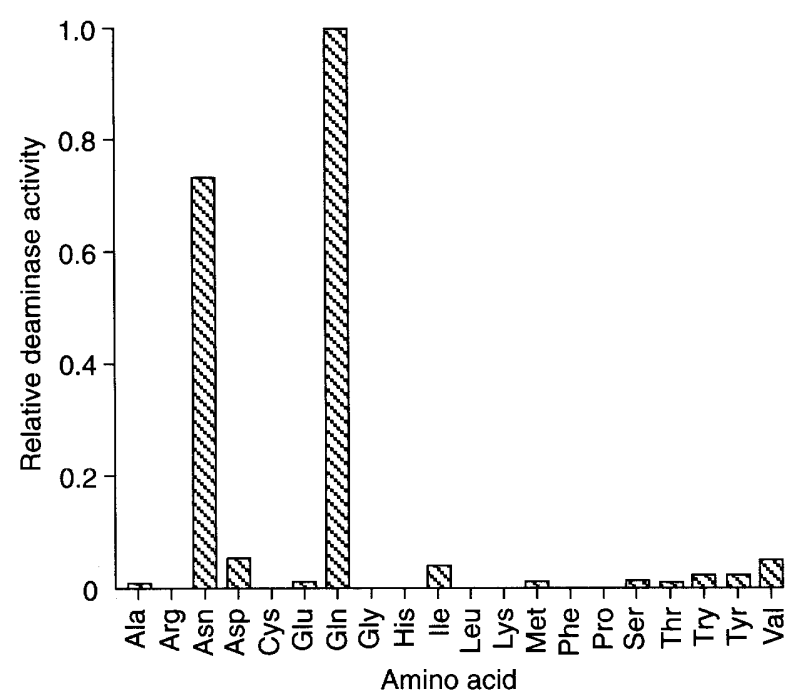

Fig. 2. Deaminase activity of $H$. pylori NCTC 11637: relative rates of activity compared to glutaminase activity; determined by the production of ammonia.

Table 2. Specific deaminase activities of $H$. pylori strains

\begin{tabular}{lccc}
\hline Strain no. & $\begin{array}{c}\text { Glutaminase } \\
\text { activity } \\
\text { (nmol/min/mg } \\
\text { of protein) }\end{array}$ & $\begin{array}{c}\text { Asparaginase } \\
\text { activity } \\
\text { (nmol/min/mg } \\
\text { of protein) }\end{array}$ & $\begin{array}{c}\text { Ratio } \\
\text { (glutaminase: } \\
\text { asparaginase } \\
\text { activities) }\end{array}$ \\
\hline NCTC 11637 & 87 & 66 & $1: 0.76$ \\
NCTC 11638 & 135 & 46.4 & $1: 0.34$ \\
NCTC 11916* & ++ & + & ND \\
Ali & 64 & 14.9 & $1: 0.23$ \\
Burke & 132 & 35.1 & $1: 0.26$ \\
Carter & 103 & 19.3 & $1: 0.18$ \\
N118 & 120 & 41.5 & $1: 0.34$ \\
G2245 & 86 & 28.7 & $1: 0.33$ \\
G2578 & 97.5 & 33.5 & $1: 0.34$ \\
G2580 & 40.7 & 22.9 & $1: 0.56$ \\
G2985 & 105 & 80.5 & $1: 0.76$ \\
G3266 & 62 & 24.3 & $1: 0.39$ \\
G3571 & 66.6 & 24.5 & $1: 0.51$ \\
\hline
\end{tabular}

++ , high activity; + moderate activity; ND, not determined. ${ }^{*}$ Specific activity not measured. linear with time. In the absence of cell suspension glutamine and asparagine were hydrolysed much more slowly, and cell suspension alone did not yield significant amounts of ammonia (Fig. 3).

The rate of glutaminase enzyme activity of $H$. pylori strain NCTC 11637 was significantly inhibited by the glutaminase specific inhibitor DON, as assayed by incubation of cell suspensions with glutamine and DON. The asparaginase activity was not inhibited by DON (Fig. 4).

Analysis of the products of the action of $H$. pylori cells on glutamine and asparagine by HPLC showed the production of glutamate and aspartate respectively (Fig. 5a and b). The sum of the molar concentrations of substrate and product decreased with time for both glutamine and asparagine. The sum of glutamine plus glutamate decreased from $9.6 \mathrm{mM}$ to $8.1 \mathrm{mM}$ and that

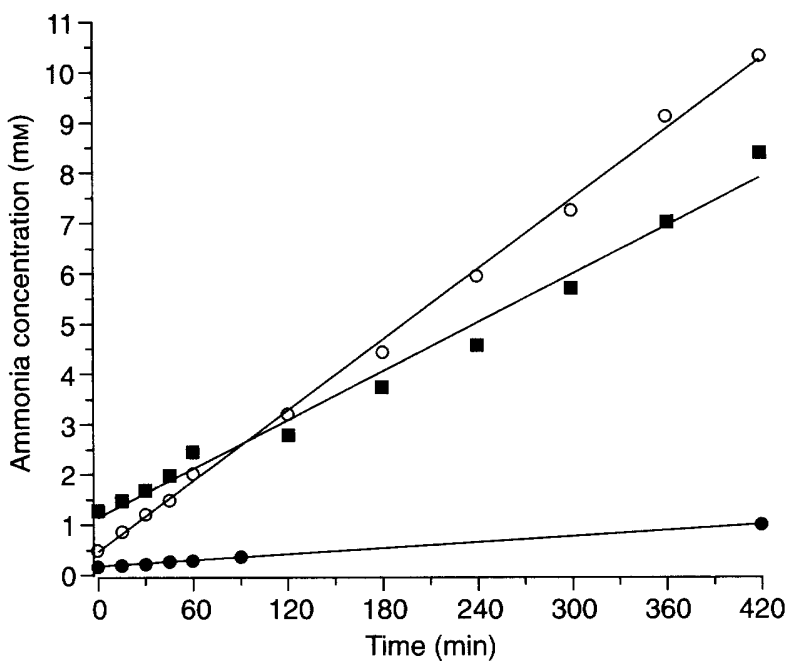

Fig. 3. Glutaminase and asparaginase activity of $H$. pylori NCTC 11637 determined by ammonia release.

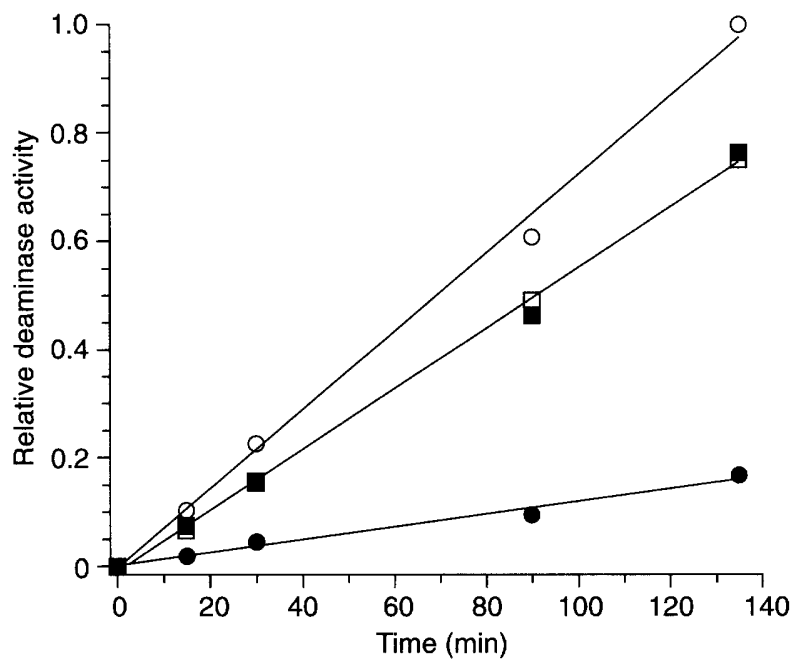

Fig. 4. Relative glutaminase $(\bullet, O)$ and asparaginase $(\boldsymbol{\square}$, $\square)$ activity of $H$. pylori NCTC 11637 in the presence $(\bullet, \square)$ and absence $(O, \square)$ of 6-diazo-5-oxo-L-norleucine (DON); compared to glutaminase activity. 


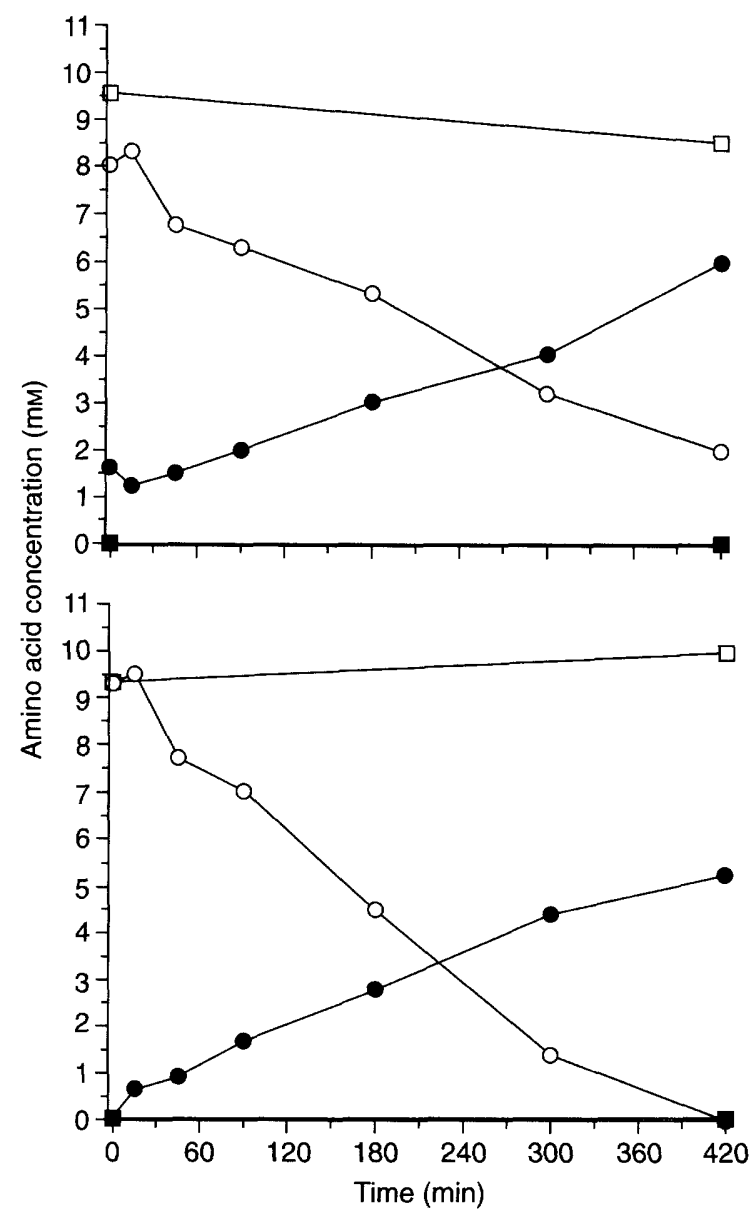

Fig. 5. (a) Glutamine utilisation and glutamate production by $H$. pylori NCTC 11637 determined by HPLC analysis: $\square$ glutamine (cell-free) control; $\square$ cell suspension control; $\bigcirc$ glutamine; glutamate. (b) Asparagine utilisation and aspartate production by $H$. pylori NCTC 11637 determined by HPLC analysis: $\square$ asparagine (cellfree) control; $\square$ cell suspension control; $O$ asparagine; aspartate.

of asparagine plus aspartate decreased from $9.7 \mathrm{mM}$ to $5.2 \mathrm{mM}$.

\section{Discussion}

Growth of $H$. pylori in a complex medium such as Brucella broth supplemented with serum or with $(2,6-$ di- $o$-methyl)- $\beta$-cyclodextrin has been described [22]. The nutritional requirements of $H$. pylori have been defined $[14,18]$ with charcoal or bovine serum albumin (BSA) as supplements. BSA cannot be regarded as totally non-nutritive, as low levels of peptidases that will hydrolyse the BSA may be produced by $H$. pylori, thus providing amino acids. Charcoal is insoluble and is impractical to use in continuous culture studies, being difficult to keep as an even suspension during addition of medium. Moreover, it cannot be filtersterilised and it interferes with culture turbidity readings. The present study demonstrated the growth of $H$. pylori in a defined continuous culture system contain- ing $\beta$-cyclodextrin instead of BSA, charcoal or the expensive supplement (2,6-di-o-methyl)- $\beta$-cyclodextrin.

The use of continuous culture enables the growth rate of an organism to be controlled by the dilution rate. Under these conditions the biomass yield is limited by the availability of nutrients. In the human host glucose is available as a nutrient, as well as amino acids and therefore glucose was included in the defined medium. The limiting nutrients in this system were not determined.

The concentration of ammonia in continuous culture in the presence of low levels of urea (Brucella brothfetal calf serum $1 \%$ ) increased gradually from $4 \mathrm{mM}$ on the day of inoculation to $18 \mathrm{mM}$ at 7 days after inoculation. The level of ammonia was considerably above that which could have been evolved from urea hydrolysis. Moreover, with the constitutive production of high levels of urease it would be expected that all the urea present would be hydrolysed rapidly. Amino acids were the only media components that were present at a concentration sufficient to facilitate the production of ammonia at the levels detected.

The ammonia concentration of the culture declined with the transition to the defined medium from the peak of $18 \mathrm{mM}$ to $5.9 \mathrm{mM}$. This reflects the higher amino acid concentration of the urea-containing Brucella broth (c. $20 \mathrm{~g} / \mathrm{L}$ ) compared to the urea-free defined medium (c. $3.4 \mathrm{~g} / \mathrm{L}$ ). Brucella broth does not contain high levels of glutamine, because the process of the preparation of the component peptones and tryptones causes its hydrolysis. Therefore, the ammonia detected must have come from other amino acids, a primary candidate being the hydrolysis of asparagine by asparaginase. Additional enzyme activities identified by Mendz and Hazell [15] that hydrolyse amino acids releasing ammonia (arginase, aspartase and serine dehydratase) would contribute by hydrolysing arginine to ornithine plus urea (which would yield ammonia upon hydrolysis), aspartate to fumarate plus ammonia, and serine to pyruvate and ammonia. The present analysis of amino acid utilisation showed that alanine, arginine, aspartate, asparagine, glutamate, glutamine, proline and serine were almost totally depleted from the culture medium when $H$. pylori was grown in the defined medium, thereby supporting the evidence for the production of the enzymes identified by Mendz and Hazell [15]. The final concentration of $5.9 \mathrm{~mm}$ ammonia is above that which could have evolved from the deamination of glutamine and asparagine. Deamination of all of the utilised amino acids would yield a maximum final concentration of ammonia of $8.9 \mathrm{mM}$.

Co-incubation of $H$. pylori with amino acids showed that both glutamine and asparagine were deaminated. In other bacterial species deamination of glutamine and asparagine has been demonstrated to be carried 
out either by enzymes specific for each amino acid (glutaminase and asparaginase) or by enzymes that deaminate both glutamine and asparagine (glutamine (asparagine)-ase) [23].

DON inhibits Escherichia coli glutaminase and Acinetobacter glutaminasificans glutamine(asparagine)-ase activity but not the asparaginase of $E$. coli [23]. The glutaminase activity of $H$. pylori is inhibited by DON and the asparaginase activity is not, indicating that there are at least two enzymes. This is supported by the different ratios of glutaminase to asparaginase activities in the different strains tested.

The presence of glutaminase and asparaginase at different ratios supports the hypothesis that there are at least two enzymes, and their presence in all the strains tested indicates that the activities are important for the nutrition or survival of the organism in the human host, or both. In experiments reported here with whole cells there was a decrease in the sum of the molar concentrations of the substrates (glutamine and asparagine) and their respective products (glutamate and aspartate). This supports the suggestion that enzymes are present that utilise these products [15] This is particularly prominent in asparagine metabolism, where the sum of the molar concentrations of asparagine plus aspartate decreased from $c .10 \mathrm{mM}$ to $5 \mathrm{~mm}$ (Fig. 5b) when H. pylori was incubated with asparagine. The aspartase activity described by Mendz and Hazell [15] produced ammonia and fumarate from the hydrolysis of aspartate, and could account for this decline. Therefore all assays involving the determination of ammonia concentration for the deamination of asparagine are affected by the aspartase activity.

It has been proposed previously that $H$. pylori deaminates phenylalanine. In the presence of phenylalanine $H$. pylori produced keto-acid (detected by ferric chloride) [24], presumably trans-cinnamate [25]; the production of ammonia was not reported [24]. Ammonia production by $H$. pylori in the presence of phenylalanine was not detected in the present study (although this finding may reflect the insensitivity of the assay). Also, neither this analysis of amino acid utilisation nor that by Mendz and Hazell [15] showed depletion of phenylalanine in the culture supernate.

The utilisation of amino acids by $H$. pylori has now been investigated extensively. This has shown that the few amino acids that are utilised are hydrolysed into the common products glutamate and pyruvate. These are further metabolised to lactate, acetate, formate, alanine and succinate $[12,15,26,27]$. A possible biochemical model from amino acid metabolism of H. pylori can be produced (Fig. 6). Products of metabolism of amino acids can be further metabolised by enzymes of the TCA cycle [28].

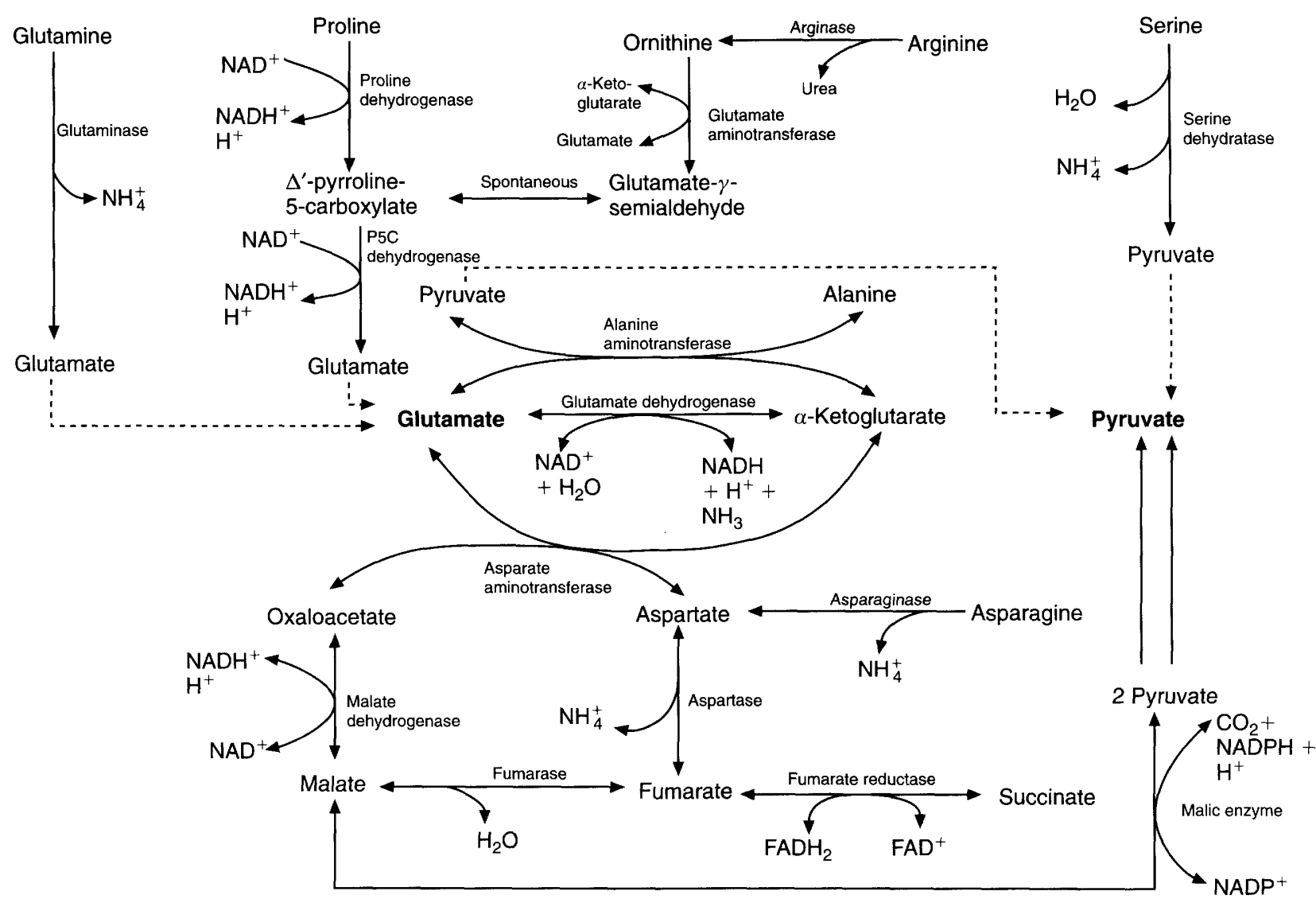

Fig. 6. Proposed biochemical pathways for the utilisation of amino acids by $H$. pylori NCTC 11637 in continuous culture in a defined medium. 
The eight amino acids identified as being utilised by $H$. pylori are non-essential for mammals. Of those amino acids not utilised by $H$. pylori, tyrosine, cysteine and glycine are conditionally non-essential. Therefore it seems that $H$. pylori is well adapted to utilise readily available non-essential amino acids as carbon energy/nitrogen sources [29].

Emphasis has been placed on the urease enzyme as the major producer of ammonia. The possibility that amino acids are deaminated by $H$. pylori has not been investigated extensively. The consequence of deamination of amino acids may not only result in increased ammonia production, but also the depletion of substrate amino acids at the site of infection. Both these factors may be of importance in the pathogenicity of $H$. pylori.

Glutamine is the major amino acid present in the serum, being also the major nitrogen carrier in the human body [30]. It is probable that glutamine diffuses from the serum/interstitial fluid or is secreted into the sub-mucus environment of $H$. pylori. The nutritional significance of glutamine for $H$. pylori is unknown. Glutamine is essential for epithelial cell health of the small intestine. Traditionally enteral or parenteral nutrition solutions have not contained glutamine, as it is unstable and gradually hydrolyses in solution. Long-term total enteral or parenteral nutrition has been linked to intestinal atrophy. Glutamine stable dipeptides such as alanyl-glutamine or glycyl-glutamine have been shown to ameliorate this effect. Infusion of glutaminase reduces levels of glutamine leading to malfunction of the intestine with associated chronic diarrhoea and villous atrophy [30].

Cells of the immune system, particularly lymphocytes and macrophages, use glutamine as an energy source $[30,31]$. Stimulated lymphocytes and macrophages show increased glutamine utilisation. During infection and trauma, under certain circumstances, the level of glutamine in serum fall, which has been linked to increased utilisation of glutamine. Depletion of glutamine at the site of infection with $H$. pylori may therefore have immunological consequences leading to persistent colonisation rather than eradication. Therefore it is possible that glutamine supplementation, perhaps combined with agents that specifically block $H$. pylori glutaminase, may improve the outcome of patients with $H$. pylori infection.

We thank Dawn Wallace and Ann Moffatt in the Department of Cardiac Surgery for their help in the amino acid analysis and protein determinations, and A. Burris and F. Lamont at the Public Health Laboratory, Gloucester Royal Hospital for providing the H. pylori strains G2245, G2578, G2580, G2985, G3266 and G3571.

\section{References}

1. Warren JR, Marshall B. Unidentified curved bacilli on gastric epithelium in active chronic gastritis. Lancet 1983; 1:
$1273-1275$

2. Marshall BJ, Warren JR. Unidentified curved bacilli in the stomach of patients with gastritis and peptic ulceration. Lancet 1984; 1: 1311-1315.

3. Parsonnet J, Friedmen GD, Vandersteen DP et al. Helicobacter pylori infection and the risk of gastric carcinoma. $N$ Engl $J$ Med 1991; 325: 1127-1131

4. Wotherspoon AC, Doglioni C, Diss TC et al. Regression of primary low-grade B-cell gastric lymphoma of mucosaassociated lymphoid tissue after eradication of Helicobacter pylori. Lancet 1993; 342: 575-577.

5. Leunk RD, Johnson PT, David BC, Kraft WG, Morgan DR. Cytotoxic activity in broth-culture filtrates of Campylobacter pylori. J Med Microbiol 1988; 26: 93-99.

6. Covacci A, Censini S, Bugnoli M et al. Molecular characterization of the $128-\mathrm{kDa}$ immunodominant antigen of Helicobacter pylori associated with cytotoxicity and duodenal ulcer. Proc Natl Acad Sci USA 1993; 90: 5791-5795.

7. Mégraud F, Bonnet F, Garnier M, Lamouliatte M. Characterization of "Campylobacter pylori" by culture, enzymic profile, and protein content. J Clin Microbiol 1985; 22: 1007-1010.

8. Hu L-T, Mobley HLT. Purification and N-terminal analysis of urease from Helicobacter pylori. Infect Immun 1990; 58: 992-998.

9. Dunn BE. Pathogenic mechanisms of Helicobacter pylori. Gasteroenterol Clin North Am 1993; 22: 43-57.

10. Mégraud F, Neman-Simha V, Brügmann D. Further evidence of the toxic effects of ammonia produced by Helicobacter pylori urease on human epithelial cells. Infect Immun 1992; 60: 1858-1863.

11. McNulty CAM, Dent JC. Rapid identification of Campylobacter pylori $(C$. pyloridis) by preformed enzymes. $J$ Clin Microbiol 1987; 25: 1683-1686.

12. Mendz GL, Hazell SL, Burns BP. Glucose utilization and lactate production by Helicobacter pylori. J Gen Microbiol 1993; 139: 3023-3028.

13. Schaffer G, Stark R, Greenman J. Glucose metabolism by Helicobacter pylori (Comment). Microbiology 1994; 140: 2179.

14. Nedenskov P. Nutritional rerquirements for growth of Helicobacter pylori. Appl Environ Microbiol 1994; 60: 3450-3453.

15. Mendz GL, Hazell SL. Aminoacid utilization by Helicobacter pylori. Int J Biochem Cell Biol 1995; 27: 1085-1093.

16. Millar MR, Pike J. Bactericidal activity of antimicrobial agents against slowly growing Helicobacter pylori. Antimicrob Agents Chemother 1992; 36: 185-187.

17. Kangatharlingam N, Amy PS. Helicobacter pylori comb. nov. exhibits facultative acidophilism and obligate microaerophilism. Appl Environ Microbiol 1994; 60: 2176-2179.

18. Reynolds DJ, Penn CW. Characteristics of Helicobacter pylori growth in a defined medium and determination of its amino acid requirements. Microbiology 1994; 140: 2649-2656.

19. Weatherburn MW. Phenol-hypochlorite reaction for the determination of ammonia. Anal Chem 1967; 39: 971-974.

20. Suleiman M-S, Wallace D, Birkett S, Angelini GD. Changes in the intracellular free amino acid pool in human saphenous vein tissue culture. Exp Physiol 1996; 81: 435-446.

21. Roberts J, Holcenberg JS, Dolowy WC. Isolation, crystalization, and properties of Achromobacteraceae glutataminaseasparaginase with antitumor activity. J Biol Chem 1972; 247: $84-90$.

22. Olivieri R, Bugnoli D, Armellini $\mathrm{D}$ et al. Growth of Helicobacter pylori in media containing cyclodextrins. $J$ Clin Microbiol 1993; 31: 160-162.

23. Zollner H. Handbook of enzyme inhibitors. Cambridge, VCH Publishers (UK) Ltd. 1989.

24. Catrenich CE, Makin KM. Characterization of the morphologic conversion of Helicobacter pylori from bacillary to coccoid forms. Scand J Gasteroenterol 1991; 26 Suppl 181: 58-64.

25. Hodgins DS. Yeast phenylalanine ammonia-lyase. Purification, properties and the identification of catalytically essential dehydroalanine. $J$ Biol Chem 1971; 246: 2977-2985.

26. Birkholz S, Knipp U, Lemma E, Kröger A, Opferkuch W. Fumarate reductase of Helicobacter pylori - an immunogenic protein. J Med Microbiol 1994; 41: 56-62.

27. Chalk PA, Roberts AD, Blows WM. Metabolism of pyruvate and glucose by intact cells of Helicobacter pylori studied by ${ }^{13} \mathrm{C}$ NMR spectroscopy. Microbiology 1994; 140: 2085-2092. 
28. Hoffmann PS, Goodwin A, Johnsen J, Magee K, Veldhuyzen van Zanten SJO. Metabolic activities of metronidazole-sensitive and -resistant strains of Helicobacter pylori: repression of pyruvate oxidoreductase and expression of isocitrate lyase activity correlate with resistance. J Bacteriol 1996; 178: $4822-4829$.

29. Salway JG. Metabolism at a glance. Oxford, Blackwell
Science. 1994.

30. Newsholme P, Costa Rosa LFBP, Newsholme EA, Curi R. The importance of fuel metabolism in macrophage function. Cell Biochem Funct 1996; 14: 1-10.

31. Castell LM, Bevan SJ, Calder P, Newsholme EA. The role of glutamine in the immune system and in intestinal function in catabolic states. Amino Acids 1994; 7: 231-243. 